Please do not remove this page

RMIT

UNIVERSITY

\title{
Influence of gas injection on viscous and viscoelastic properties of Xanthan gum
}

Bobade, Veena; Cheetham, Madalyn; Hashim, Jamal; Eshtiaghi, Nicky

https://researchrepository.rmit.edu.au/esploro/outputs/9921862829001341/filesAndLinks?institution=61RMIT_INST\&index=null

Bobade, V., Cheetham, M., Hashim, J., \& Eshtiaghi, N. (2018). Influence of gas injection on viscous and viscoelastic properties of Xanthan gum. Water Research, 134, 86-91.

https://doi.org/10.1016/j.watres.2018.01.071

Document Version: Accepted Manuscript

Published Version: https://doi.org/10.1016/j.watres.2018.01.071

Repository homepage: https://researchrepository.rmit.edu.au

(c) 2018 Elsevier Ltd. All rights reserved.

Downloaded On 2023/04/26 13:22:03 +1000

Please do not remove this page 
Thank you for downloading this document from the RMIT Research Repository.

The RMIT Research Repository is an open access database showcasing the research outputs of RMIT University researchers.

RMIT Research Repository: http://researchbank.rmit.edu.au/

\section{Citation:}

Bobade, V, Cheetham, M, Hashim, J and Eshtiaghi, N 2018, 'Influence of gas injection on viscous and viscoelastic properties of Xanthan gum', Water Research, vol. 134, pp. 86-91.

See this record in the RMIT Research Repository at:

https://researchbank.rmit.edu.au/view/rmit:47049

Version: Accepted Manuscript

\section{Copyright Statement:}

(C) Creative Commons Attribution-NonCommercial-NoDerivatives 4.0 International License.

\section{Link to Published Version:}

https://dx.doi.org/10.1016/j.watres.2018.01.071 
1

2

3

4

5

$6{ }^{1}$ RMIT University, School of Civil, Environmental and

7 chemical Engineering, 124 La Trobe St, Melbourne, Vic

83000 , Australia.

$9 \quad$ * Corresponding Author: Nicky.eshtiaghi@rmit.edu.au

\section{Abstract}

11 Xanthan gum is widely used as a model fluid for sludge to

12 mimic the rheological behaviour under various conditions

13 including impact of gas injection in sludge. However, there is

14 no study to show the influence of gas injection on rheological

15 properties of xanthan gum specifically at the concentrations at

16 which it is used as a model fluid for sludge with solids

17 concentration above $2 \%$.

18 In this paper, the rheological properties of aqueous xanthan

19 gum solutions at different concentrations were measured over a

20 range of gas injection flow rates. The effect of gas injection on

21 both the flow and viscoelastic behaviour of Xanthan gum

22 (using two different methods - a creep test and a time sweep

23 test) was evaluated. The viscosity curve of different solid

24 concentrations of digested sludge and waste activated sludge 
25 were compared with different solid concentrations of Xanthan

26 gum and the results showed that Xanthan gum can mimic the

27 flow behaviour of sludge in flow regime.

28 The results in linear viscoelastic regime showed that increasing 29 gas flow rate increases storage modulus $\left(G^{\prime}\right)$, indicating an 30 increase in the intermolecular associations within the material 31 structure leading to an increase in material strength and solid

32 behavior. Similarly, in creep test an increase in the gas flow

33 rate decreased strain\%, signifying that the material has become

34 more resistant to flow. Both observed behaviour is opposite to

35 what occurs in sludge under similar conditions.

36

37 The results of both the creep test and the time sweep test

38 indicated that choosing Xanthan gum aqueous solution as a

39 transparent model fluid for sludge in viscoelastic regime under

40 similar conditions involving gas injection in a concentration

41 range studied is not feasible. However Xanthan gum can be

42 used as a model material for sludge in flow regime; because it

43 shows a similar behaviour to sludge.

44 Key Words:

45 Gas injection; Xanthan gum; Viscoelastic Properties; Flow

46 behaviour; Herschel-Bulkley Model 
48 Xanthan gum is a naturally occurring polysaccharide, produced

49 by fermenting glucose with the bacteria Xanthomonas

50 campestris, with a backbone of $\beta-(1,4) \tau-D$-glucose (Kennedy et

51 al. 2015). The primary structure of the material is shown in

52 Figure 1. The structure consists of repetitive pentasaccharide

53 units formed with two glucose units, two mannose units, and

54 one glucuronic acid unit, with the molar ratio being 2.8:2.0:2.0

55 (García-Ochoa et al. 2000)

56 When mixed in aqueous solution, xanthan gum exists in an

57 ordered helical conformation, either single or double stranded.

58 The molecular structure of the material actively contributes to

59 its rheological properties, with the structuration pattern of the

60 solutions being related to hydrogen-bridging between lateral

61 chains and binding networks formed by molecular

62 entanglement (Laneuville et al. 2013). Additionally, Figure 2

63 shows that dehydration can affect the conformation of

64 molecules, in which the intra and intermolecular ester bonds

65 cause crosslinking with an extended polymer structure (Bueno

66 et al. 2013).Xanthan solutions are known to have a non-

67 Newtonian rheology, with a shear-thinning behaviour under

68 increasing shear rate. It has been widely reported that an initial

69 yield stress is exhibited by xanthan solutions must be overcome

70 for the solution to start flowing (García-Ochoa et al. 2000,

71 Marcotte et al. 2001, Song et al. 2006). Only when the 
72 magnitude of stress reaches above the yield stress, the structure

73 is broken down, orienting the polymer chains to align with flow

74 stream. The yield stress is attributed to the molecular structure

75 of the material and a large number of hydrogen bonds which

76 exist in the solution (Bradshaw et al. 1983).

77 Xanthan gum is widely used as a model fluid for sludge to

78 mimic sludge shear thinning behaviour (García-Ochoa et al.

79 2000, Kennedy et al. 2015, Saha and Bhattacharya 2010).

80 Sludge is the residual, semi-solid slurry produced from waste

81 water treatment process. It is also well known that sludge is a

82 mixture of complex biological material and difficult to

83 characterize (Eshtiaghi et al. 2013, Ratkovich et al. 2013,

84 Seyssiecq. et al. 2003). Moreover, the opaque nature of sludge

85 makes it difficult to estimate the accurate bubble behaviour and

86 impacts on hydrodynamics of the process. Changes in complex

87 rheological behaviour of sludge over time because of aging and

88 microbial activity cause variations in sludge viscosity making it

89 difficult to optimize the process performance (Bajón Fernández

90 et al. 2015, Baudez and Coussot 2001). Since sludge

91 rheological properties have a significant impact on the design

92 parameters of the equipment used in the process, which

93 potentially can affect energy consumption, and the cost of

94 operation (Yang et al. 2009), Xanthan gum is used as a model

95 fluid for sludge under gas injection for optimising and

96 modelling of process equipment in sludge treatment plant 
97 (Bhattacharjee et al. 2015, Cao et al. 2016). Gas injection in 98 sludge is recognized to play a significant role in oxygen 99 transfer, mixing efficiency and energy consumption in 100 membrane bioreactor and waste activated sludge process 101 (Åmand and Carlsson 2012, Bobade et al. 2017, Ratkovich et 102 al. 2013, Seyssiecq et al. 2008). The gas injection also has a 103 major impact on sludge physical properties like extra cellular 104 polymeric substances (EPS), soluble COD, particle size, etc., 105 and changes its rheological properties influencing the 106 efficiency of the process (Drews 2010, Meng et al. 2006).

107 Although, the rheological properties of xanthan gum have been 108 extensively studied under varying conditions of pressure 109 (Laneuville et al. 2013), temperature (Marcotte et al. 2001), 110 gum concentration and ionic strength (Vega et al. 2015); there 111 is no study reporting the impact of gas injection on rheological 112 properties of xanthan gum. The objective of this work is to 113 investigate the effect of gas injection on the rheological 114 properties (apparent viscosity and viscoelastic modulus) of 115 xanthan gum at different solids concentrations and gas flow 116 rates by using dynamic time sweep test and creep test. As well 117 as to compare it with the sludge behaviour under similar 118 experimental condition (Bobade et al. 2017). 
122 Xanthan gum solutions of $0.3 \mathrm{wt} \%, 0.4 \mathrm{wt} \%, 0.5 \%$ and $0.6 \mathrm{wt} \%$

123 were prepared by mixing xanthan gum powder (supplied by

124 Sigma Aldrich) in deionized water to form a homogenous

125 solution. Solutions were mixed using a stirrer at approximately

$126700 \mathrm{rpm}$ until the solution became homogenous. The solution

127 was allowed to rest for one day, to remove air bubbles from the

128 solution.

\section{2.2Apparatus}

130 Rheological measurements were performed using a

131 commercially available hybrid stress controlled (HR3)

132 rheometer from TA Instruments equipped with Grooved bob

133 geometry with an outer diameter of $0.0149 \mathrm{~m}$, and $0.042 \mathrm{~m}$

134 length. A custom designed plexi glass cup (inner diameter:

$1350.1 \mathrm{~m}$, length: $0.1 \mathrm{~m}$ ) was used. A stainless steel porous disk

136 (outer diameter: $0.1 \mathrm{~mm}$, thickness: $0.0016 \mathrm{~m}$, porosity: $40 \%$,

137 from SINTEC Australia) was used at the bottom for the gas

138 sparging. The gas flow rate was varied from 0.5 litres per

139 minute (LPM) to 2 LPM i.e., $8.33 \times 10^{-6}\left(\mathrm{~m}^{3} / \mathrm{s}\right)$ to $3.33 \times 10^{-5}$

$140\left(\mathrm{~m}^{3} / \mathrm{s}\right)$ using a gas mass flow meter from AALBORG at a

141 pressure of 10 Psi. All measurements were carried out at room

142 temperature.

$143 \quad 2.3$ Rheological measurements 
144 To understand the impact of gas injection on apparent viscosity

145 of Xanthan gum, a flow curve measurement was carried out

146 using following procedure. The sample was pre sheared at high

147 shear rate "310 $\mathrm{s}^{-1 "}$ [the maximum shear rate without

148 turbulence in this cup with grooved bob geometry] for $300 \mathrm{~s}$

149 and then allowed to rest for $120 \mathrm{~s}$, to obtain an identical sample

150 before each flow curve measurement. The viscosity of the

151 sample was then measured at the shear rate from $0.001 \mathrm{~s}^{-1}$ to

$152100 \mathrm{~s}^{-1}$. Further, the preshearing stage was repeated and the gas

153 was injected with 0.5 LPM for $1200 \mathrm{~s}$, and then the flow curve

154 was measure. The above procedure is repeated for all the gas

155 flow rates and all concentrations in duplicate.

156 Since grooved bob geometry with a wide gap $(0.042 \mathrm{~m})$ was

157 used, the flow curves were recalculated using equations (1) and

158 (2) (Estellé et al. 2008)

$159 \quad \tau_{R i}=\frac{M}{\left(2 \pi H R_{i}^{2}\right)}$

160

$\dot{\gamma}=2 M \frac{d \Omega}{d M}, \tau_{c} \leq \tau_{y} \leq \tau_{b}$

161 , Where,

162

$M=$ Torque (N.m),

163

$\mathrm{H}=$ Height of the bob $(\mathrm{m})$,

164

$\mathrm{R}_{\mathrm{i}}=$ Radius of the bob,

165

$\mathrm{d} \Omega / \mathrm{dM}=\left(\Omega_{\mathrm{j}}-\Omega_{\mathrm{j}-1}\right) /\left(\mathrm{M}_{\mathrm{j}}-\mathrm{M}_{\mathrm{j}-1}\right)$

$\tau_{\mathrm{y} ;} \tau_{\mathrm{c}} ; \tau_{\mathrm{b}}=$ yield stress, stress at the cup and stress at

167

the bob, respectively $(\mathrm{Pa})$. 
168 To understand the macro or micro structural changes occurring

169 in Xanthan gum due to gas dispersion, a time sweep

170 measurement was performed using following pattern: Preshear

171 the Xanthan gum at a high shear rate of $310 \mathrm{~s}^{-1}$ and allow the

172 short rest period of 120 s to remove the history of the sample

173 and obtain the identical sample for each test. Afterward,

174 oscillation time sweep test at $0.15 \%$ strain and $1 \mathrm{~Hz}$ frequency

175 for 1500 seconds is carried out and preshearing step is repeated.

176 After repeating the preshearing step, the gas is injected for 20

177 mins and time sweep test is carried out again. This procedure is

178 repeated for all the four concentrations and 4 gas flow rates.

179 Similarly, to understand the impact of gas injection on elastic

180 deformation of xanthan gum, a creep test at very low stress of

181 3pa was carried out using the same procedure. This procedure

182 is similar to gas injection procedure into sludge which was

183 done by Bobade et al. (2017)

\section{Result and discussion}

\subsection{Impact of gas injection on flow behaviour}

187 The stress response over a range of shear rates was measured to 188 understand the flow behaviour of Xanthan gum. For different 189 solids concentration viscosity curves were plotted at different 190 gas flow rates. One sample graph is presented in Fig 3 (Veena 191 and Nicky 2017). The figure shows that at $0.3 \mathrm{wt} \%$ xanthan 
192 gum for different gas flow rates there is negligible change in

193 viscosity at given shear rate. Similar trend in viscosity curve

194 was observed for all the 4 concentrations at 4 different gas flow

195 rates (See supplementary Fig. S1). The uncertainty of change in

196 this observation is $\pm 5 \%$ if the instrument is not calibrated

197 properly.

198 It is interesting to note that similar negligible change in

199 viscosity of sludge with gas injection was also observed by

200 Bobade et al. (2017). The reason for negligible change in

201 viscosity can be bubble coalescence occurring in Xanthan gum

202 because of its high viscosity (Bobade et al. 2017, Fransolet et

203 al. 2005). Thus the results clearly indicated that gas injection

204 has no impact on viscosity of xanthan gum.

205 In addition, to show which solids concentration of xanthan gum

206 can simulate 2 and $3.6 \mathrm{wt} \%$ digested and $3 \mathrm{wt} \%$ waste activated

207 sludge, the flow behaviour of xanthan gum was also compared

208 with the waste activate sludge (WAS) and digested sludge flow

209 behaviour as shown in Fig.4. The digested sludge data in

210 Figure 4 was extracted from Eshtiaghi et al. (2016). The Figure

211 clearly shows that $2 \mathrm{wt} \%$ digested sludge is close to $0.3 \mathrm{wt} \%$

212 and 0.4wt\% Xanthan gum. However, there was a significant

213 difference between the viscosity curves for both $3 \mathrm{wt} \%$ WAS

214 and 3.6wt\% Digested sludge with even highest solid

215 concentration $(0.6 \mathrm{wt} \%)$ of xanthan gum. The Herschel Bulkley

216 parameters for $3 \mathrm{wt} \%$ WAS and $3.5 \mathrm{wt} \%$ digested sludge were 
217 much greater than xanthan gum for all the concentrations as

218 shown in Fig 5.

219 The value of Herschel Bulkley parameters for each 220 concentration of Xanthan gum; WAS and digested sludge is 221 presented in Table 1. It is clear from Table 1 yield stress value 222 and flow consistency index of $3.6 \mathrm{wt} \%$ digested sludge and $2233 \mathrm{wt} \%$ WAS is much higher than equivalent properties of the

224 highest concentration of xanthan gum. So much higher solid 225 concentrations of xanthan gum as a simulant is needed to be 226 used in order to mimic flow behaviour of $3.6 \mathrm{wt} \%$ digested 227 sludge and $3 \mathrm{wt} \%$ WAS in liquid regime. property of Xanthan gum in linear viscoelastic region (Solid regime)

231 To investigate the impact of gas injection on the viscoelastic 232 property of xanthan gum in the linear region, the influence of 233 gas was studied by both (1) creep test, and (2) time sweep test 234 as shown in Fig. 6. (Veena and Nicky 2017) Fig. 6A 235 demonstrates that, during creep test, the strain $\%$ for $0.3 \mathrm{wt} \%$ 236 xanthan gum decreased by increasing the gas flow rate. The 237 decreasing values for strain \% indicate more resistance to the 238 constant load and a lower degree of deformation of material. 239 The less strain \% values means more solid behaviour and 240 difficult to deform as a result of being stronger material (Saha 
241 and Bhattacharya 2010). Thus, xanthan gum solidifies and

242 becomes harder to deform as the gas injection rate increases.

243 Similarly, Fig. 6B reveals that, as the gas flow rate increased

244 both the viscous (loss) modulus (G”) and elastic (storage)

245 modulus (G') were increased while $G^{\prime}$ was larger than $G^{\prime \prime}$ at all

246 times. It means that that xanthan gum solidified in the linear

247 viscoelastic regime as the gas injection rate was increased

248 (Mezger 2011). Furthermore, the solid behavior of xanthan

249 gum has dominant impact compared to the liquid behaviour of

250 xanthan gum, indicating that material was still in solid regime.

251 It was also observed that an increase in G" at different gas flow

252 rates is negligible in comparison to the impact of gas injection

253 on G'. A similar observation was observed for all the four

254 solid concentrations at four different gas flow rates in both

255 creep test and time sweep test (see supplementary Fig. S2 and

256 Fig. S3). The uncertainty of change in this observation is $\pm 5 \%$

257 if the instrument is not calibrated properly.

258

259 The main possible reason behind xanthan gum solidifying

260 behaviour can be, change in molecular structure at a micro or

261 macro level due to the injection of nitrogen gas, which results

262 in a more entangled structure by altering crosslinking. In the

263 same way, the thickening behaviour has been observed in

264 similar polysaccharide materials such as mamaku gum

265 (Jaishankar et al. 2015), whereby the material exhibits 
266 thickening behaviour when sheared below yield stress.

267 Jaishankar et al. 2015 explained that thickening behaviour of

268 polysaccharide at low shear rate occurs because of an

269 interaction between intra and intermolecular associations. It

270 means at low shear rates the molecule remains in equilibrium

271 due to the disentanglement time being longer, because of which

272 molecule gets elongated and results into thickening behaviour.

273 As most of the characteristics of all types of polysaccharides

274 are same (Lapasin and Pricl 1995), when the gas is injected in

275 the xanthan gum solution, the stress developed by gas injection

276 is minimal and not sufficient to disentangle the molecular

277 structure. Hence, the polymer chains became extensionally

278 deformed and partially elongated, increasing exposure for local

279 molecular interactions and physical crosslinking to form

280 helices. The presence of helix structure and hydrogen bonds in

281 xanthan gum show resistance to stress and flow is suggested by

282 Bradshaw et al. (1983). Furthermore, as the gas velocity

283 increases with increased flow rate, there is an increase in the

284 shear stress between the bubble-liquid interface (Majumder et

285 al. 2007). The increase in shear stress increases molecular

286 elongation and thus the exposure for further molecular

287 interactions, therefore contributing to an increased material

288 strength, solution viscosity, and solid behaviour. Surprisingly,

289 this behaviour of xanthan gum was not consistent with the

290 sludge behaviour under similar conditions i.e., at low strain and 
291 stress corresponding to linear region. Bobade et al. (2017)

292 have shown that increase in gas injection rate reduces the

293 viscoelastic properties of sludge using same experimental setup

294 and at strain and stress corresponding to linear region. This

295 reduction of viscoelastic properties of sludge is due to

296 breakdown of floc structure as a result of imposed shear by gas

297 injection. Moreover, the creep tests done under similar

298 condition showed that sludge deforms more by increasing gas

299 injection flow rate. This means weaker structure (see insets in

300 Fig 6). Bobade et al. (2017) proved weakening of sludge

301 structure through environmental scanning electron microscopic

302 analysis by observing more porous structure.

\section{Conclusion}

304 In this present study, we investigated how the rheological

305 properties of xanthan gum at different solids concentration

306 changes due to gas injection.

307 In flow region, the flow curve of xanthan gum showed

308 negligible change in the apparent viscosity of in xanthan gum

309 solution as gas injection flow rate increased. However, in linear

310 viscoelastic region, the creep test and time sweep test proved

311 that gas injection increased the storage and loss modulus which

312 is an indication of strengthening of molecular structure. This

313 could be due to deformation of the molecular structure of

314 xanthan gum and increasing the crosslinking within an 
316 stress and showing more solid like behaviour in the linear

317 viscoelastic region. Thus although xanthan gum behaves

318 similar to the sludge in the liquid regime, the behaviour of

319 xanthan gum contradicts with the sludge behaviour in the solid

320 regime which means Xanthan gum is not suitable as a model

321 fluid for sludge under gas injection below yield stress point.

\section{Acknowledgements}

323 The Authors acknowledge RMIT University for providing the

324 Australian post graduate scholarship to V. Bobade, to carry out

325 the research.

\section{References}

327 Åmand, L. and Carlsson, B. (2012) Optimal aeration control in a 328 nitrifying activated sludge process. Water Research 46(7), 329 2101-2110.

330 Bajón Fernández, Y., Cartmell, E., Soares, A., McAdam, E., Vale, 331 P., Darche-Dugaret, C. and Jefferson, B. (2015) Gas to liquid 332 mass transfer in rheologically complex fluids. Chemical 333 Engineering Journal 273, 656-667.

334 Baudez, J.C. and Coussot, P. (2001) Rheology of aging, 335 concentrated, polymeric suspensions: Application to pasty 336 sewage sludges. Journal of Rheology 45(5), 1123-1140.

337 Bhattacharjee, P.K., Kennedy, S., Eshtiaghi, N. and 338 Parthasarathy, R. (2015) Flow regimes in the mixing of 339 municipal sludge simulant using submerged, recirculating jets. 340 Chemical Engineering Journal 276(Supplement C), 137-144.

341 Bobade, V., Baudez, J.C., Evans, G. and Eshtiaghi, N. (2017) 342 Impact of gas injection on the apparent viscosity and 343 viscoelastic property of waste activated sewage sludge. Water 344 Research 114, 296-307.

345 Bradshaw, I.J., Nisbet, B.A., Kerr, M.H. and Sutherland, I.W. 346 (1983) Modified xanthan-its preparation and viscosity. 347 Carbohydrate Polymers 3(1), 23-38. 
349 Synthesis and swelling behavior of xanthan-based hydrogels.

350 Carbohydrate Polymers 92(2), 1091-1099.

351 Cao, X., Zhao, Z., Cheng, L. and Yin, W. (2016) Evaluation of a 352 Transparent Analog Fluid of Digested Sludge: Xanthan Gum 353 Aqueous Solution. Procedia Environmental Sciences 354 31(Supplement C), 735-742.

355 Drews, A. (2010) Membrane fouling in membrane 356 bioreactors-Characterisation, contradictions, cause and 357 cures. Journal of Membrane Science 363(1), 1-28.

358 Eshtiaghi, N., Markis, F., Yap, S.D., Baudez, J.C. and Slatter, P. 359 (2013) Rheological characterisation of municipal sludge: A 360 review. Water Research 47(15), 5493-5510.

361 Eshtiaghi, N., Markis, F., Zain, D. and Mai, K.H. (2016) 362 Predicting the apparent viscosity and yield stress of digested 363 and secondary sludge mixtures. Water Research 95, 159-164.

364 Estellé, P., Lanos, C. and Perrot, A. (2008) Processing the 365 Couette viscometry data using a Bingham approximation in 366 shear rate calculation. Journal of Non-Newtonian Fluid 367 Mechanics 154(1), 31-38.

368 Fransolet, E., Crine, M., Marchot, P. and Toye, D. (2005) 369 Analysis of gas holdup in bubble columns with non-Newtonian 370 fluid using electrical resistance tomography and dynamic gas 371 disengagement technique. Chemical Engineering Science 372 60(22), 6118-6123.

373 García-Ochoa, F., Santos, V.E., Casas, J.A. and Gómez, E. (2000) 374 Xanthan gum: production, recovery, and properties. 375 Biotechnology Advances 18(7), 549-579.

376 Jaishankar, A., Wee, M., Matia-Merino, L., Goh, K.K.T. and 377 McKinley, G.H. (2015) Probing hydrogen bond interactions in a 378 shear thickening polysaccharide using nonlinear shear and 379 extensional rheology. Carbohydrate Polymers 123, 136-145.

380 Kennedy, J.R.M., Kent, K.E. and Brown, J.R. (2015) Rheology of 381 dispersions of xanthan gum, locust bean gum and mixed 382 biopolymer gel with silicon dioxide nanoparticles. Materials 383 science $\&$ engineering. C, Materials for biological applications 384 48, 347-353.

385 Laneuville, S.I., Turgeon, S.L. and Paquin, P. (2013) Changes in 386 the physical properties of xanthan gum induced by a dynamic 387 high-pressure treatment. Carbohydrate Polymers 92(2), 23273882336.

389 Lapasin, R. and Pricl, S. (1995) Rheology of Industrial 390 Polysaccharides: Theory and Applications, pp. 250-494, 391 Springer US, Boston, MA.

392 Majumder, S.K., Kundu, G. and Mukherjee, D. (2007) Pressure 393 drop and bubble-liquid interfacial shear stress in a modified 
gas non-Newtonian liquid downflow bubble column. Chemical

395 Engineering Science 62(9), 2482-2490.

396 Marcotte, M., Taherian Hoshahili, A.R. and Ramaswamy, H.S. 397 (2001) Rheological properties of selected hydrocolloids as a 398 function of concentration and temperature. Food Research 399 International 34(8), 695-703.

400 Meng, F., Zhang, H., Yang, F., Zhang, S., Li, Y. and Zhang, X. 401 (2006) Identification of activated sludge properties affecting 402 membrane fouling in submerged membrane bioreactors. 403 Separation and Purification Technology 51(1), 95-103.

404 Mezger, T.G. (2011) The rheology handbook : for users of 405 rotational and oscillatory rheometers, Vincentz Network, 406 Hanover, Germany.

407 Ratkovich, N., Horn, W., Helmus, F.P., Rosenberger, S., 408 Naessens, W., Nopens, I. and Bentzen, T.R. (2013) Activated 409 sludge rheology: A critical review on data collection and 410 modelling. Water Research 47(2), 463-482.

411 Saha, D. and Bhattacharya, S. (2010) Hydrocolloids as 412 thickening and gelling agents in food: a critical review. Journal 413 of food science and technology 47(6), 587-597.

414 Seyssiecq, I., Marrot, B., Djerroud, D. and Roche, N. (2008) In 415 situ triphasic rheological characterisation of activated sludge, 416 in an aerated bioreactor. Chemical Engineering Journal 142(1), 417 40-47.

418 Seyssiecq., Ferrasse and Roche (2003) State-of-the-art: 419 rheological characterisation of wastewater treatment sludge.

420 Biochemical Engineering Journal 16(1), 41-56.

421 Song, K.-W., Kim, Y.-S. and Chang, G.-S. (2006) Rheology of 422 concentrated xanthan gum solutions: Steady shear flow 423 behavior. Fibers and Polymers 7(2), 129-138.

424 Veena, B. and Nicky, E. (2017) Viscoelastic properties of 425 Xanthan gum $(0.3 \%$ to $0.6 \%)$ at different gas injection rate 426 (0.5LPM to 2LPM), doi: 427 https://doi.org/10.6084/m9.figshare.5683921.

428 Vega, E.D., V“'squez, E., Diaz, J.R.A. and Masuelli, M.n.A. 429 (2015) Influence of the lonic Strength in the Intrinsic Viscosity 430 of Xanthan Gum. An Experimental Review. Journal of Polymer 431 and Biopolymer Physics Chemistry 3(1), 12-18.

432 Yang, F., Bick, A., Shandalov, S., Brenner, A. and Oron, G. 433 (2009) Yield stress and rheological characteristics of activated 434 sludge in an airlift membrane bioreactor. Journal of 435 Membrane Science 334(1-2), 83-90. 436 